It is surprising that rathor little is said about the important part played by $\mathrm{Ca}^{++}$in transmitter release. Events which follow the release of transmitter are considered in chapter five. This rather short chapter includes an outline of drugreceptor kinetics, and the restrictions to their application, as well as a brief section on conductance changes in the postsynaptic membrane of the neuromuscular junction.

Chapters seven and eight consider the much more complex problems facing investigators of central nervous synaptic mechanisms, and the authors ambitiously aim to discuss "an overall strategy for the study of synaptic transmission in the central nervous system". In this, they have only partially succeeded, but they do provide a useful summary of the achievements of electrophysiological analysis of central nervous synaptic mechanisms. The final chapter considers the interpretation of extracellular field potentials in the central nervous system. The emphasis on a knowledge of the microscopic organization of neural elements is sensible and timely.

'There is a useful appendix which deals with such practical and important matters as anaesthesia and composition of saline solutions. There are also brief summaries of the effects of temperature, $p \mathrm{H}$ and osmotic pressure on a number of synaptic events.

The aim of this book is to provide practical guidance to experimentalists and in this it must be judged successful. It will be welcomed by workers in the subject as well as by advanced students who may be thinking of a research career. The book is pleasantly produced in the standard format of these monographs, but at five guineas it seems, even for these days, expensive.

R. H. Adrian

\section{FUNCTIONING OF THE KIDNEY}

\section{Mechanisms of Urine Concentration}

By S. E. Dicker. (Monographs of the Physiological Society, No. 20.) Pp. $x+214$. (Arnold: London, February 1970.) 65s.

Ar one time the cortex was thought to be the most active and interesting part of the kidney, but in the past two decades it has become apparent that the cortex and medulla of the kidney, like those of the suprarenal gland, are, in effect, two almost separate organs which differ from one another in their development, their blood supply and their functions. This book deals largely with tho mcdulla, the part of the kidney principally concerned with the "facultative" rather than the "obligatory" reabsorption of water.

Chapter one, which is appropriately entitled "Chapter One", gives a mastcrly introduction to the subject and initiates the newcomer into the mysteries of osmolar and free water clearances. The author goes on to discuss the osmotic gradient in the medulla, the role of counter. current multiplior and exchange systems in establishing and maintaining the gradient, and the initial formation and chemical claboration of the urine. This is followed by a detailed account of the chemistry of the antidiuretic hormone (ADH) and its possible modes of action, with particular reference to its effect on the permeability of membranes. Next, renal function in the newborn mammal is described and, finally, the last chapter discusses current views on the subject and raises a number of unsolved questions.

This is a book which needed to be written and it will provide a most helpful and thought provoking survey of the literature for all rescarch workers who are interested in the mechanisms of urine production. It will also be a valuable introduction for the newcomer to the field, although he must remember that, as is mentioned in the preface, the book is intended to be a monograph and not a comprehensive review. It is not difficult to find refercnees which have been omitted, no doubt deliberately, for the selection of material has obviously been influenced by the author's own extensive research work and by his own personal views. A different author, for instance, might perhaps have chosen to write less about Ginetzinsky's hypothesis concerning the role of hyaluronidase in urinary concentration and included more about the functions of the medullary circulation. This individual approach, however, adds greatly to the interest and character of the book and makes it much more stimulating than a detailed and exhaustive review of the literature, valuable though this may be.

There is no doubt that Professor Dicker's monograph will be enthusiastically received by all nephrologists and, although the references include papers published as late as 1969 , the expansion of knowledge in this sphere is so rapid that one hopes that the author is already collecting data for his next edition.

D. B. MoFfa'

\section{BIOLOGY OF CONCEPTION}

\section{Schering Symposium on Mechanisms involved in Conception}

Berlin, March 13 to 15, 1969. Edited by Gerhard Raspé. (Advances in the Bioseiences, 4.) Pp. viii + 472. (Pergamon Press: Oxford, London and New York; Vieweg und Sohn: Braunschweig, 1970.) 60 DM.

ThIs symposium is primarily concerned with capacitation and fertilization, gamete transport, implantation and the control of corpus luteum function.

The section on capacitation mostly involves discussion of events in the reproductive tract of the female rabbit, which have been most intensively studied, and includes only brief references to other species. The important role of follicular fluid in inducing the sperm acrosome reaction is insufficiently emphasized, except in Bedford's description of the morphology of capacitation. This author presents a balanced account of a confusing subject. On. the development of the human egg, Edwards offers an intriguing explanation of anomalies associated with the ageing oocyte. $\mathrm{He}$ also describes maturation and early stages of fertilization of human ova in vitro, and considers possible clinical applications.

Of the various factors which influence the rate of $\mathrm{ogg}$ transport along the oviduct, the effects of compounds acting on tubal musculature seem to be more important than tubal fluid secretion and ciliary action. Lobel gives a detailed account of the variations in the cytology and histochemistry of the rat oviduct under different hormonal conditions. Dorfman considers the effects of chlormadinone on preimplantation events in animals and women.

It is evident from Kirby's experiments that the study of ectopic implantation of embryos can greatly assist tho investigation of normal implantation and development, espccially the endocrinology and immunology of preg. nancy. The sequential nature of the hormonal requirements for implantation in the rat is elegantly demonstrated by Psychoyos, who also suggests that the progesteronedominated uterus can secrete a factor which promotes a state of diapause.

The control of corpus luteum function is judiciously reviewed by Caldwoll. Unilatoral autotransplantation of the sheep ovary and reproductive tract to a superficial site is discussed by McCracken as a way of investigating corpus luteum regulation. The technique permits study of the hormonal control of ovarian secretion in the unstressed animal, and seems to have considerable potential in several areas of research. The interesting possibility of functional luteolysis by enzymatic inactivation of progesterone is considered, but in view of other evidence the existence of a luteolytic factor remains implied yet unproven.

The diversity of the subject of this symposium is reflected in the widely varying interests of the participants; it is valuable to have so much information on the biology of conception in one volume. Several of the review 